This PDF is a selection from a published volume from the National Bureau of Economic Research

Volume Title: Social Security Programs and Retirement around the World: Historical Trends in Mortality and Health, Employment, and Disability Insurance Participation and Reforms

Volume Author/Editor: David A. Wise, editor

Volume Publisher: University of Chicago Press

Volume ISBN: 0-226-90309-5; 978-0-226-90309-5

Volume URL: http://www.nber.org/books/wise11-1

Conference Date:

Publication Date: September 2012

Chapter Title: Disability and Social Security Reforms: The French Case

Chapter Author(s): Luc Behaghel, Didier Blanchet, Thierry Debrand, Muriel Roger

Chapter URL: http://www.nber.org/chapters/c12389

Chapter pages in book: (p. 301 - 326) 


\title{
Disability and Social Security Reforms The French Case
}

\author{
Luc Behaghel, Didier Blanchet, Thierry Debrand, \\ and Muriel Roger
}

\subsection{Introduction}

It is well known that France is characterized by low levels of employment in the fifty-five to sixty-four age bracket, compared to other developed countries. Until recently, the specific role of disability benefits in explaining these early exits did not attract a lot of academic attention. One obvious reason for this lack of interest is that this role is quantitatively limited. The French pattern of early transitions out of employment is basically explained by the low age at "normal" retirement and by the importance of transitions through unemployment insurance (UI) and preretirement schemes (PR) before access to normal retirement. The role of these various routes has been repeatedly demonstrated in previous contributions to these International Social Security (ISS) series volumes and again in the last one (Ben Salem et al. 2010). These routes have exempted French workers from massively relying on disability motives for early exits, contrarily to the situation that prevails in some other countries where normal ages are high, unemployment benefits low, and preretirement schemes almost nonexistent.

Yet this role of disability remains interesting to examine in this French case, at least for prospective reasons. The current tendency is toward increasing the normal retirement age and toward a more restricted access to unem-

Luc Behaghel is associate professor at the Paris School of Economics and an INRA researcher at UMR Paris-Jourdan Sciences Économiques. Didier Blanchet belongs to the French National Statistical Institute (INSEE) and is affiliated with the Research Center in Economics and Statistics (CREST). Thierry Debrand is research director at the Institute for Research and Information in Health Economics (IRDES). Muriel Roger is associate professor at the Paris School of Economics.

For acknowledgments, sources of research support, and disclosure of the authors' material financial relationships, if any, please see http://www.nber.org/chapters/c12389.ack. 
ployment benefits or preretirement for senior workers. In such a context, the disability route may gain some renewed importance in the future, acting as a substitute to these other early retirement schemes whose coverage will progressively decline. Investigating whether such substitution effects have been already observed in the past can shed some light on their potential impact for the future.

More generally, we observe an increasing interest in the French pension debate for the connection between retirement behavior and health (Struillou 2003; Volkoff and Bardot 2004; Molinié 2006; Blanchet and Debrand 2008). We all know that different categories of workers end up their working lives with very uneven health conditions and very uneven life expectancies, sometimes directly linked to past working conditions. How should pension reforms take this kind of inequality into account, especially when poor health directly results from work conditions? This question remains currently unanswered. The pension reform that took place in 2003 was expected to be followed by a negotiation between social partners on this specific issue, but this negotiation has been unfortunately unable to provide any form of tangible result, and this issue is again central in debates generated by the new reform in 2010. At the time this chapter is written, the main components of this reform project are a progressive shift of the minimum retirement age from sixty to sixty-two, and a parallel shift from sixty-five to sixty-seven for the age at which a full rate pension can be obtained whatever the length of one's career. Consequences of such a shift for workers with bad health, low life expectancies, or who have been exposed to hard working conditions have been one of the main objections raised by opponents to the reform. The proposed answer to this concern has consisted in maintaining the threshold of sixty for people with a level of impairment of at least 10 percent, and one wonders in which proportions this possibility will be used as a new instrument of early exits.

It is with these considerations in mind that we shall examine the French experience of interaction between pension reforms and take-up of disability benefits and, more generally, the importance of health considerations in the design of pension policies.

We shall first concentrate on substitution effects. Even if the disability route has always played a limited role in France, its importance is not negligible (Barnay and Jeger 2006), and it has fluctuated over the past decades. These fluctuations can be used to test the substitutability hypothesis: disability loses importance when other routes become more widely accessible and, conversely, when these routes are reformed in a more restrictive way. After a brief presentation of the trend of the French old workers participation to the labor market in section 8.2, section 8.3 will first recall the main historical changes that occurred in the pension system, in early retirement schemes, and in disability benefits and focus more specifically on interactions that took place until the early eighties. We shall more specifically focus 
on two major historical changes going in the direction of more generous pensions and a lower take-up of disability benefits: the first one took place during the 1970s (the Boulin law) and the second one in 1983, when the normal retirement age was lowered to sixty. The consequences of these changes have been large enough to allow observation of substitution effects at the macro level.

Section 8.4 will go on along the same vein focusing on two post-1990 changes going in the opposite direction. The first one is the 1993 pension reform that restricted the access to full pension benefits at sixty. Up to now, this reform did not affect a very large proportion of the population, and this implies that substitution effects are difficult to observe on macro-series. But such effects exist and can be identified on micro data. We shall present results from this quasi experiment following Bozio (2006). The second episode relates to sickness leaves covered by health insurance. The first half of the 2000s witnessed an increase in these sickness leaves that has been sometimes interpreted as another manifestation of the substitution effects between early retirement schemes and the disability route to retirement. Strengthened control over these sickness leaves after 2003 dramatically reduced their role for older workers.

In short, the message of sections 8.3 and 8.4 is that, whatever the episode considered, institutional changes or changes in the intensity of controls are sufficient to explain changes in the take-up of disability benefits. Given this evidence, it might appear hardly necessary to check that these changes are uncorrelated with global health trends. We shall, nevertheless, examine this question in section 8.5. One good reason for exploring this question is that an absence of correlation at the macro level can still go along with a significant interaction at a more micro level. Moreover, the fact that the take-up of disability benefits essentially reflects institutional changes does not mean that those who claim these benefits do not actually face real health problems. At the macro level, section 8.5 confirms the lack of correlation between health and labor market status: the past decades have been a period of uninterrupted improvement in average health. But micro data can help build a more detailed story that reconciles this macro view with the increasing concern for health considerations in the pension debate. An improvement of average health can go along with the persistence of a significant health dimension of pension problems if the dispersion of health status is large and a fortiori if this dispersion is increasing. Micro data suggest that such a phenomenon may be at work. If this trend is confirmed, the question that we have raised in the preceding retains all its importance: if health is an obstacle to remaining on the labor market for an important share of the population, how should pension policy address the case of these people? The general improvement of health and the lack of historical connection between health and the take up of disability benefits do not mean that health can be neglected in the design of retirement policies. 


\subsection{General Labor Force Participation Trends and Pension Reforms}

To have a clear view of the role of disability benefits in the general pattern of retirement routes of older workers in France, we first give a brief recall on the general labor force participation (LFP) trends in the past decades. Moreover, we underline the link between LFP and the pension reforms implemented during the same period.

Data on labor force participation and pathways to retirement are provided by labor force surveys (LFS) conducted by the French National Statistical Institute (INSEE) since 1950. We use the 1968 to 2005 waves of this LFS. Trends in labor force participation for men and women are given in figures 8.1 and 8.2. Participation rates of senior workers aged sixty-five and over are quite low. For men aged sixty to sixty-four, we note a large decrease over the period. We observe the same trend for women but in smaller proportions due to the counteracting influence of increased attachment to the labor force for successive cohorts.

The difference between men and women is still more pronounced for the fifty-five to fifty-nine age group. For men, after a period of relative stability at the beginning of the period, we observe a drop just after 1982 and then a new period of stability. For women, the arrival in the fifty-five to fifty-nine group of women increasingly attached to the labor market fully dominates the trend toward earlier exits.

Previous work from Ben Salem et al. (2010) has underlined the correlation between changes in senior labor force participation and the key dates of

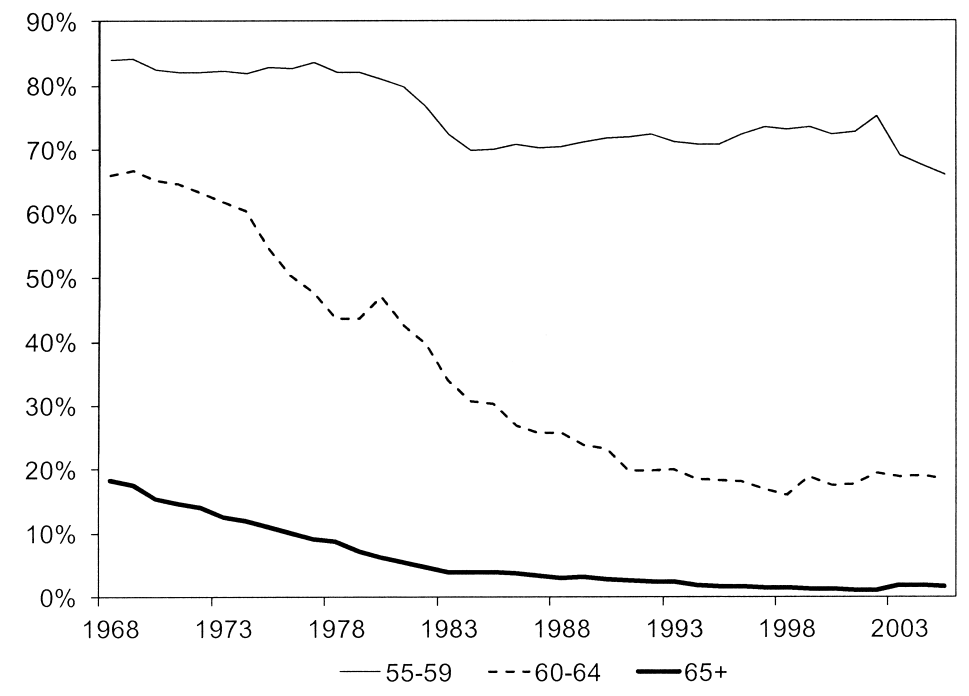

Fig. 8.1 Labor force participation for men, 1968 to 2005 Source: INSEE. 


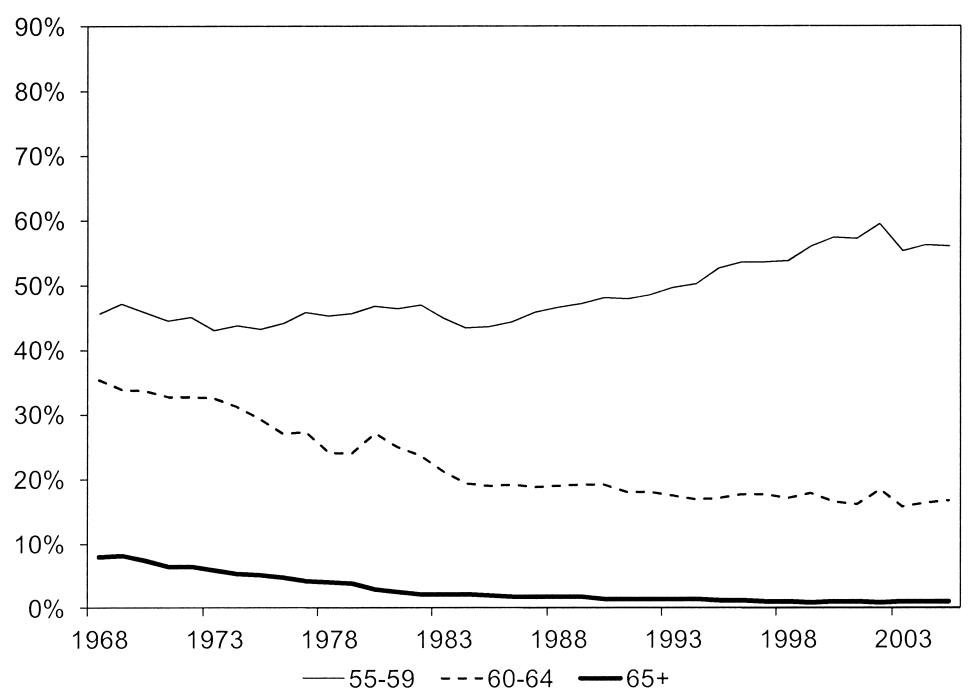

Fig. 8.2 Labor force participation for women, 1968 to 2005

Source: INSEE.

retirement reforms or labor market policies toward senior workers in France. Until 1983, the decline in LFP for the sixty to sixty-four age group has been due to the opening of retirement at sixty for some specific subgroups of the population and to the development of early retirement schemes essentially targeted to this age bracket. For this age group, the small accident that is observed in 1980 is a pure statistical artifact due to the transition through the age group of the small cohorts born between 1915 and 1919. Because LFP rates are higher at sixty than they are at sixty-four, the arrival of small cohorts first depresses the average LFP rate for the whole five-year group and, conversely, when the bulk of these small cohorts are in the second half of the age group. If we abstract from this accident, we see that the trend has been almost continuous. The impact of the 1983 reform has been essentially to replace early retired people by normal retirees.

Since then, the 1993 and 2003 reform have introduced changes that, in the long run, should reincrease LFP rates for the sixty to sixty-four group, but consequences of these reforms are still negligible. The reason is that these reforms did not suppress the possibility to get a pension at sixty and relied instead on another parameter, which is the number of years of contributions requested for this pension to be a full rate one. This parameter had been fixed at 37.5 years of contributions in 1983. The 1993 reform made it increase gradually from 37.5 years to 40 years between cohorts 1933 and 1943, but only for private-sector employees. The 2003 reform extended this forty-year condition to public-sector employees (progressively between 2003 and 2008) and now imposes a further strengthening for all workers, first from forty to 
forty-one years between 2008 and 2012 and then in line with changes in life expectancy, all that combined with changes in the incentives to retire either before or after this full rate. If these reforms did not result until now in large changes in participation rates, it is because these new conditions, until now, have affected only a limited proportion of the population: cohorts currently retiring generally started working before twenty and are still frequently able to validate forty or forty-one years of contribution at sixty. There is also the fact that changes in incentives to retire before the full rate have changed in a way that makes it less penalizing, at least for private-sector employees. There is also the fact that, since 2003, some of these employees - those having started working very early - have benefited from the possibility to retire as soon as they get their forty years of contributions, without needing to wait until sixty. This aspect of the reform has been introduced to make the reform more acceptable to the public opinion, and it has been precisely targeted to low-skilled workers with long careers who are more likely to reach the fifty-five to fifty-nine brackets in bad health.

The consequences of this latter disposition are visible at the very end of the lines for the fifty-five to fifty-nine age group on figures 8.1 and 8.2, with significant drops both for men and women although, here again, some perturbations could be attributed to the transition, through the age group, of cohorts of very uneven size born during and just after World War II and also to a break in the series in 2003 due to the shift from an annual to a continuous survey. ${ }^{1}$

Then, going backward in the past with this fifty-five to fifty-nine year age group and focusing on men for whom the impact of retirement and early retirement policies is not blurred by other trends, we see that the major event for this age group is the drop during the first half of the 1980s. This drop can be understood as a temporary consequence of lowering the normal retirement age to sixty. This lowering mechanically resulted in the disappearance of early retirement in the sixty to sixty-four bracket but also led to the development of new flows of early retirees in the fifty-five to fifty-nine group. However, this time, public authorities decided to put these new flows under stricter control, and the drop in the LFP rate stopped in 1985. Since then, with the exception of the post-2003 episode, policies have been able to just stabilize the LFP rate.

\subsection{The Role of Disability Benefits: Long-Term Trends}

What has been the relative importance of the disability route over these decades?

1. From 1968 to 2002, the households included in the Labor Force Survey sample were interviewed in March of three consecutive years with one-third of the households replaced each year. Since 2003, the households included in the French LFS are interviewed six consecutive quarters with one-sixth of the households replaced each quarter. 
Figure 8.3 uses labor force surveys and some other data sources to give an evaluation of the relative importance of this route compared to other possible pathways out of the labor force. The proxy that is used is the status of the individual the year before his or her sixtieth birthday. Data go back to 1983 , that is, they only cover the period where the normal retirement age is sixty. Moreover, data on sickness leave by age are only available after 1997; before that date, workers in sickness leave are recorded as employed. All over this period, we see a decrease in the share of people still in employment just before their sixtieth birthday and an increase in the shares of people in early retirement or benefiting from unemployment insurance benefits. Yet, all over the period, the number of people going through disability insurance or sickness leave is not negligible, amounting to between 5 percent and 8 percent of the population. We will now focus on this route, using additional statistics specific to this route and covering a longer time period.

First of all, some explanations are required concerning the organization of this disability route. Even if disability is not a predominant route out of the labor force in the French system, the idea that disability is a basic underlying motive for access to retirement has been historically important in the

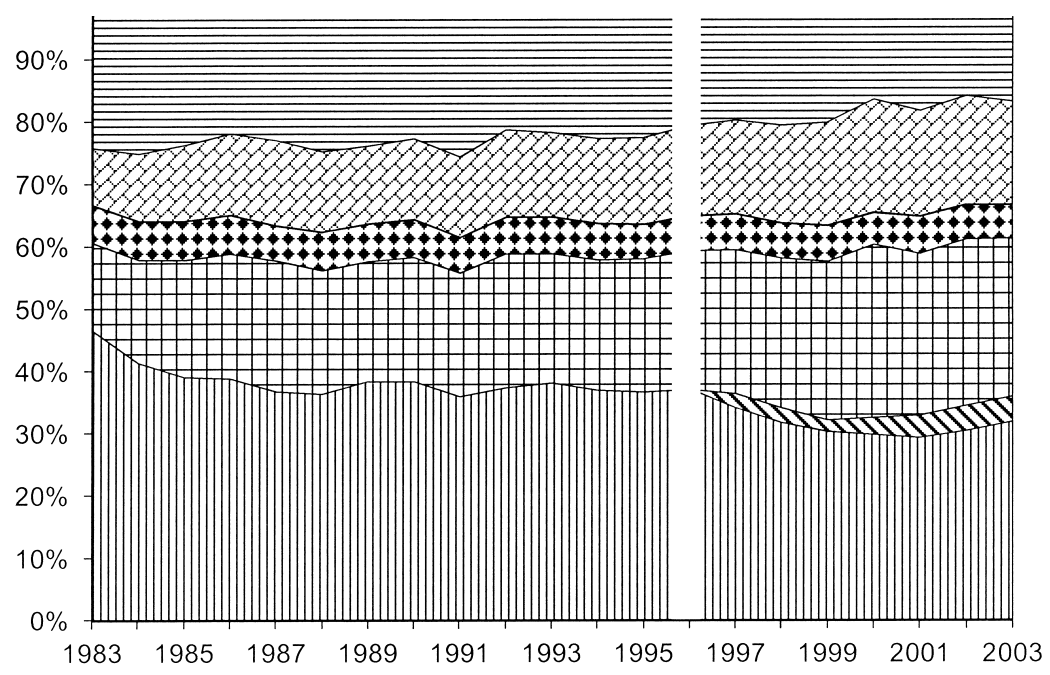

$\boxminus$ Other OLF $₫$ Early retirement Disability pension $\square$ Unemployment $\mathbf{8}$ Sickness leave $\mathbb{\square}$ Employed

Fig. 8.3 Pathways to retirement, men and women

Sources: Enquête Emploi; Unédic; DARES; CNAM; and CNAV.

Note: Pathways are proxied by the situation at age fifty-nine (see Enquête Emploi) corrected with administrative data on unemployment (see Unédic), early retirement (see DARES) and complemented with administrative data on sickness leave (see CNAM) and inflows from "pension d'invalidité" to "pensions d'inaptitude" (see CNAV). The break in the series indicates that data on sickness leave are missing before 1997; before that date, workers in sickness leave are recorded as employed. 
foundation of French social security. This goes back to consequences of the Great Depression. It had resulted in very high unemployment rates for workers above fifty, and this has led, in 1941, under the Vichy government, to the creation of the AVTS (Allocation aux Vieux Travailleurs Salariés) providing early retirement for workers above sixty excluded from the labor force either for health or economic reasons.

The employability issue was also at the heart of the creation of the current system of Social Security in 1945. At that time, the risque vieillesse (oldage risk) was clearly characterized as the risk of living beyond an age at which the individual becomes unable to maintain his or her standard of living through labor force participation, be it for health or other reasons. The designers of the system had initially considered that the age of sixty-five was an acceptable proxy for this age but already allowed an earlier access, as soon as sixty, either for people already benefiting from disability insurance before this age (retraite pour ex-invalides) or for people declared inapt for work at this age even if they were not previously benefiting from disability benefits (retraite pour inaptitude). This second category remained, however, highly selective: it required a disability rate of 100 percent, it was limited to people having worked for at least thirty years and provided a benefit being, at the maximum, equal to 40 percent of the average of past wages. ${ }^{2}$ This was higher than the rate of replacement for people claiming early retirement at sixty without this disability motive but remained little attractive. Until the beginning of the 1970s, this system was, therefore, little used, mostly by men, with women more frequently resorting to the retraite pour ex-invalides.

A more dynamic phase for the pension d'inaptitude took place during the 1970s. From a general point of view, this period has been a period of increasing generosity for the pension system, in particular with the aim of reducing the prevalence of poverty among elderly people (it was one of the aspects of the "new society" program of the post-1968 Chaban-Delmas government). This period was also marked by the strong union pressure in favor of lowering the normal retirement age to sixty for the entire population that ultimately led to retirement at sixty in 1983. During this period, that demand remained unsatisfied, but the Boulin reform in 1971 opened several possibilities for earlier exits for various categories of population, including a move toward less selective and more generous rules for the pension d'inaptitude: the threshold for the rate of disability was lowered to 50 percent, the condition of having worked thirty years or more was suppressed, and benefits were increased to 50 percent of the average wage, that is, in line with a normal full rate pension.

This mechanically led to an increased importance of this route, but, as shown on figure 8.4 , the incidence of this change was more pronounced for

2. The disability rate measures the intensity of limitations encountered by the disabled person. 


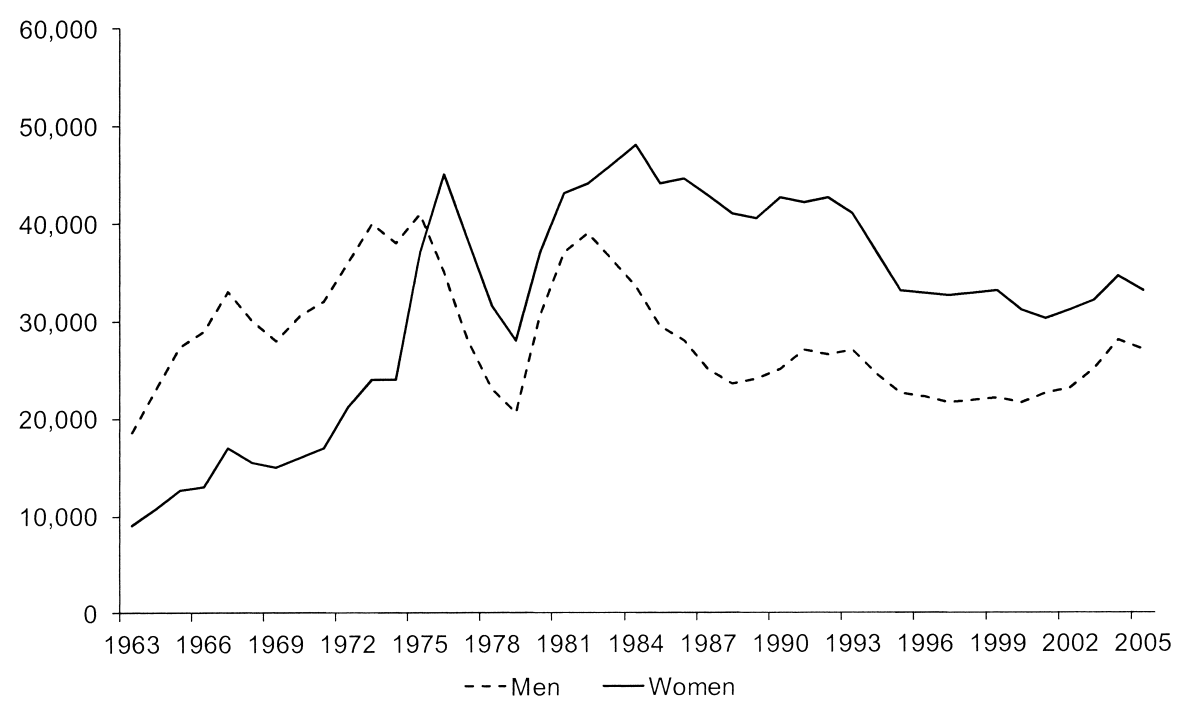

Fig. 8.4 "Pensions d'inaptitude": Total flows

Source: CNAV in Omnès (2006).

women, because men, at the same period, started benefiting from the development of the early retirement route, financially more attractive garantie de ressources and allocation spécifique du fonds national pour l'emploi, especially at the end of the 1970s. On the whole, the share of pensions d'inaptitude in the yearly flow of new pensioners increased over this period, albeit with oscillations, and finally peaked at 30 percent of total exits in 1983 (see figure 8.5).

It is just after that peak, that access to a full pension at age sixty became possible for the large majority of the population, the only condition being to have contributed to the pension system for at least 37.5 years. In this context, claiming for a pension d'inaptitude became useless for a large share of people. We note in figure 8.6 that the average pension amount for normal retirement became at least twice higher than disability benefits. Those who still had a reason to rely on this route were people reaching the age of sixty in bad health and with incomplete careers. Their share in the total flow of new pensioners is now comprised between 10 and 15 percent.

Did subsequent pension reforms alter this picture? As mentioned, the 1993 reform gradually increased the number of years of contribution required for a full pension. The 2003 reform went further in the same direction. As already shown, these two reforms have had only small upward effects on retirement ages until now. It is, therefore, not surprising that figure 8.4 does not exhibit significant moves in flows of disabled people. To analyze whether these reforms have started reorienting part of the flows toward the disability route, we must look at a micro level and analyze whether disability take-up 


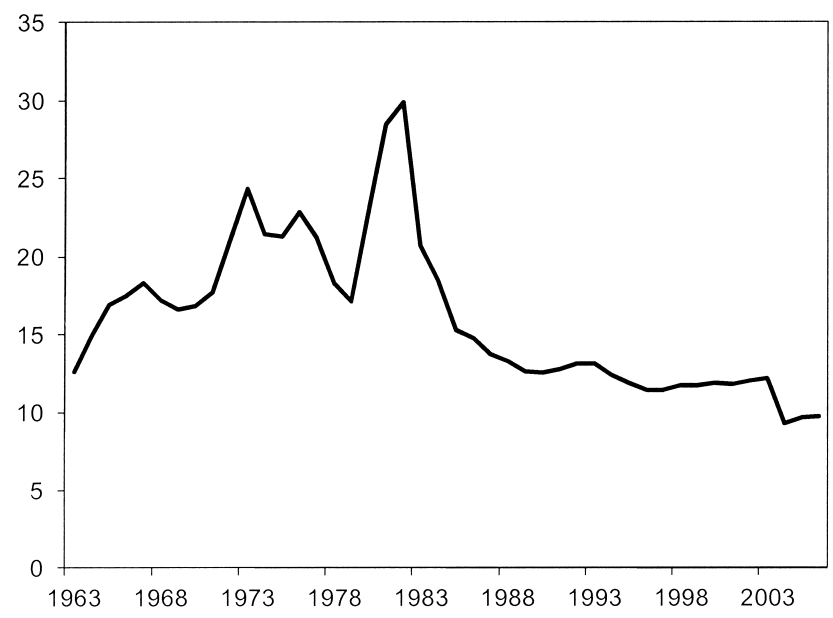

Fig. 8.5 "Pensions d'inaptitude": Percentage of the flow of new retirees Source: CNAV.

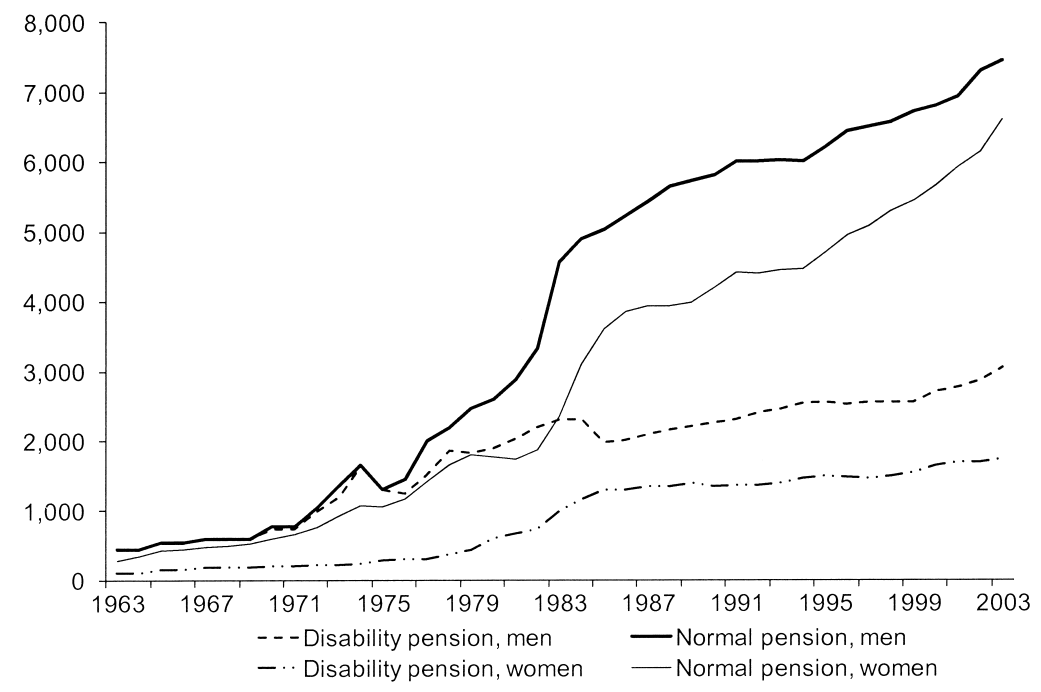

Fig. 8.6 Average pension amount: Normal pensions and "pensions d'inaptitude," 1963 to 2003 (in euros)

Source: CNAV in Omnès (2006).

has significantly increased among these people who have been hurt by the pension reform. Figure 8.3 also suggests looking at another related route in more details because there seems to be a move in the number of people benefiting from sickness leaves around the 2003 reform. This is the subject of the next section. 


\subsection{Two Quasi Experiments}

\subsubsection{The 1993 Pension Reform: Disability Pensions as a Substitute to Normal Pensions?}

The 1993 reform is the first reform in France that aimed at delaying retirement. It reduced the average full-rate pension amount (by introducing a longer period to compute the reference wage) and gradually increased the length of contribution required to get the full replacement rate. Access to disability pensions ( pensions d'inaptitude) remained unchanged. As a consequence, the reform increased the relative attractiveness of disability pensions for workers who were no longer eligible for a full-rate pension at age sixty in the normal pension scheme (due to an insufficient contribution length) but were potentially eligible for a disability pension. These workers basically had three options: (a) keep claiming a normal pension at age sixty at the cost of a high penalty; ${ }^{3}$ (b) delay claiming until reaching the required number of quarters for a normal pension; (c) apply for a disability pension at age sixty. Our goal is to assess the role played by the third option.

The impact of the 1993 reform is, unfortunately, hardly detectable from aggregate data (such as in figure figures 8.3 to 8.5), as the reform only affected about 8 percent of the workers (the wage earners of the private sector with 131 to 160 quarters of contribution at age sixty retiring through a normal pension). However, Bozio (2006) shows that it can be detected from micro data, applying a difference-in-difference approach to an administrative, exhaustive data set. In what follows, we summarize and discuss his results.

The identification of the reform rests on the comparison of workers with the same completed contribution length at age sixty over different birth cohorts. With a given contribution length (e.g., 151 quarters), older cohorts (e.g., born in 1934) are eligible for a full-rate pension at the first retirement age (sixty), whereas younger cohorts (e.g., born in 1935) need additional contribution quarters. Comparing the retirement behavior of these two groups, therefore, identifies the impact of increased contribution requirements. The identification is made robust to possible cohort trends using workers unaffected by the reform given their completed contribution lengths as a control (e.g., workers having contributed 152 quarters at age sixty).

For a representative worker aged sixty who has contributed the required number of quarters for a full-rate pension, increasing the contribution requirement by a quarter (a) increases the average retirement age through the normal pension scheme by about two months and (b) increases the probability of receiving a disability pension by 13 percentage points (Bozio 2006,

3. The replacement ratio was reduced by 10 percentage point per year of missing contribution. 
tables 2.4 and 2.7). In other words, the three types of responses are observed; some workers keep retiring at sixty through the normal pension scheme; some delay claiming and retirement; ${ }^{4}$ last, a significant share of workers switch to disability pensions. Interestingly, the effects of the 1993 reform are smaller for workers missing more than a quarter of contribution at age sixty. Even before the reform, these workers did not have access to normal pensions at a full rate at age sixty; they were, therefore, already induced to apply for a disability pension, and the impact of the 1993 reform may be small. On average, Bozio (2006) finds that a one-quarter increase in required contribution increases the probability of receiving a disability pension by 2 percentage points.

Overall, even though they are not visible on aggregate data, these substitution effects are sizeable. The 1993 natural experiment is, therefore, useful from a prospective viewpoint. For instance, if the same substitution effects persists for cohorts born in the 1960s and 1970s for which the 1993 reform should be binding for one worker out of two (due to the increase in age at labor market entry), disability pensions may become a significant route to retirement. However, the interpretation of these effects remains an open question: one cannot conclude from the results whether the reform induced a pure disclosure effect - workers with health problems who used to rely on the normal pension scheme come to use disability schemes that are aimed at them - or whether it generated a moral hazard problem - workers that are not targeted by disability pensions use them as a way to escape the new contribution requirements.

\subsubsection{The Impact of Tighter Control on \\ Long-Term Sickness Leaves for Older Workers}

The sharp increase in sickness benefits that occurred at the beginning of the 2000s in France has been a matter of debate (Lê and Reynaud 2007; Kusnik-Joinville et al. 2006). Between 1997 and 2003, aggregate sickness benefits rose from an index of 100 to 140 before falling back to 125 by 2005 . Changes in the population size and structure as well as the decline of unemployment can explain about half of the rise (the rest remaining unexplained); as for the drop after 2003, it has been widely attributed to the tighter controls that were implemented (Kusnik-Joinville et al. 2006). Indeed, the number of controls for short-term sickness leaves increased from 34,000 in 2003 to 250,000 in 2005; and since 2005, long-term leaves (above sixty days) undergo systematic control.

None of the previous studies has explored whether this rise and fall of sickness benefits in France has varied by age. This is the question we consider here, using original administrative data from the French public health insurance administration (Caisse Nationale d'Assurance Maladie [CNAM]). Indeed, older workers in the late 1990s and early 2000s had specific incen- 
tives to rely on sickness benefits, as some of the early retirement schemes were being phased down quite rapidly (the number of recipients of an early retirement scheme, at age fifty-five to fifty-nine, dropped from 230,000 in 1997 to 130,000 in 2005). Unemployment (without search requirement after age fifty-six or fifty-seven) largely acted as a substitute (the number of recipients increasing from 270,000 to 400,000 over the same period), but long-term sickness leaves may also have played a role. Moreover, the sudden restriction to sickness benefits in 2004 to 2005 through tighter control may have had a stronger impact on older workers if they were using sickness benefits as one route to retirement among many, as opposed to younger workers who could only rely on sickness benefits in case of health problems.

Figure 8.7 provides evidence in favor of these two hypotheses. It shows the evolution of sickness benefits per capita (in 1998 euros), for different age groups among men (i.e., the total amounts of sickness benefits received by a given age group over its size in the full population in order to correct for demographic shifts). All age groups display an upward trend over the 1997 to 2008 period, with years 2000 to 2003 standing out above that trend. However, the magnitude of the 2000 to 2003 "bump" is much larger for workers aged fifty-five to sixty-four. In particular, the decrease in benefits that occurs in the overall population after 2003 seems to be fully driven by the older age groups: other groups only display a slowdown in growth after 2004 to 2005 . Figure 8.8 shows quite similar patterns for women, though the bump is slightly less apparent.

In order to control for fixed differences across birth cohorts and for age effects, we conduct a difference-in-difference analysis. This analysis uses the

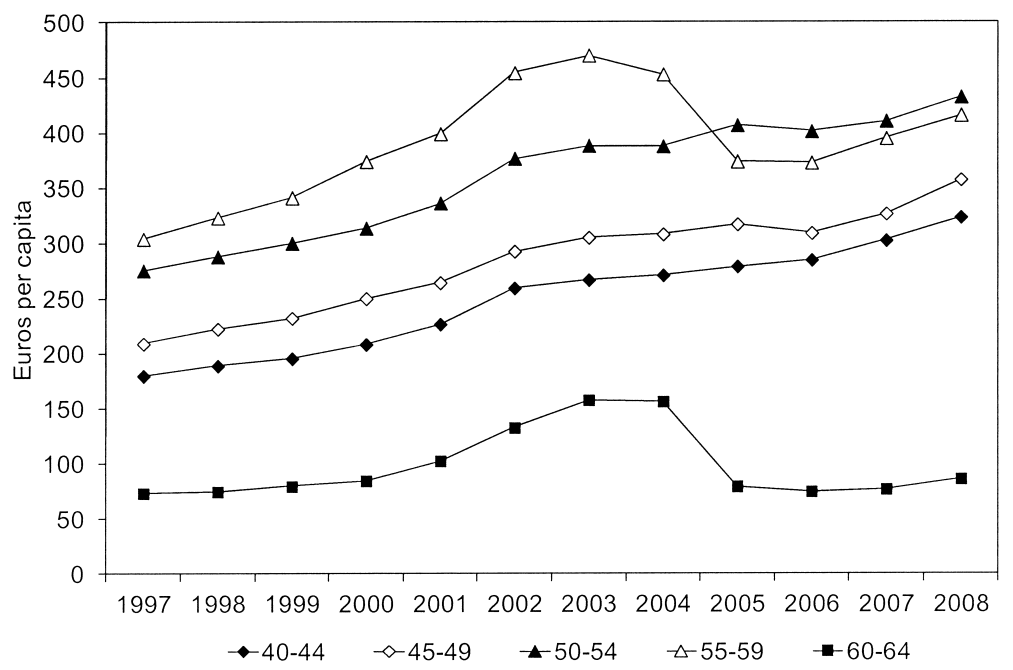

Fig. 8.7 Sickness benefits for men by age group, 1997 to 2008

Note: Benefits per capita are computed as the total spending on sickness benefits for a given age group, divided by the population size of that group. 


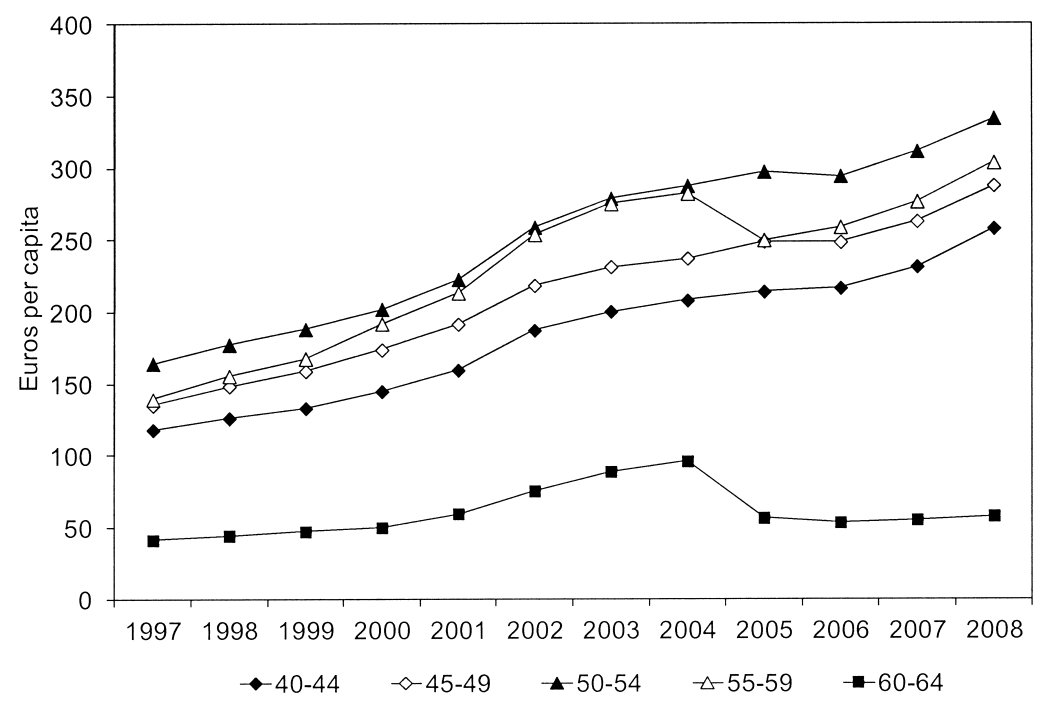

Fig. 8.8 Sickness benefits for women by age group, 1997 to 2008

Note: Benefits per capita are computed as the total spending on sickness benefits for a given age group, divided by the population size of that group.

same administrative data as in the previous graphs, that is, data grouped by five-year age groups. This data limitation implies that we observe a given five-year birth cohort only every five years. For instance, we observe the 1944 to 1948 birth cohorts in 1998, when they are fifty to fifty-four years old, in 2003, when they are fifty-five to fifty-nine, and in 2008, when they are sixty to sixty-four. As "controls," we use the adjacent cohorts, that is, the 1949 to 1953 birth cohorts (observed in 2003 and 2008 when they are fifty to fifty-four and fifty-five to fifty-nine, respectively), and the 1939 to 1943 birth cohorts (observed in 1998 and 2003 when they are fifty-five to fifty-nine and sixty to sixty-four, respectively).

We start by computing the impact of an easy access to sickness benefits for workers aged fifty-five to fifty-nine. To do so, we compare the evolution of benefits for the 1944 to 1948 cohorts (that reach age fifty-five to fifty-nine in 2003 at a time of loose controls) to the following cohorts (who reach age fifty-five to fifty-nine after the restrictions in 2008). That is, we contrast two cohorts that reach age fifty-five to fifty-nine (a decisive age in terms of retirement pathways) at a time of loose controls versus tightened controls on sickness benefits. The benefits per capita are displayed in panel A of table 8.1 (left part). For the 1944 to 1948 cohorts, benefits per capita increased from 288 to 470 euros between 1998 and 2003. As 2003 was a year when benefits were easily accessible for all ages, part of this rise may indicate the impact of loose controls over benefits for workers aged fifty-five to fifty-nine. Of course, part of it may also be due to the mere effect of age. 


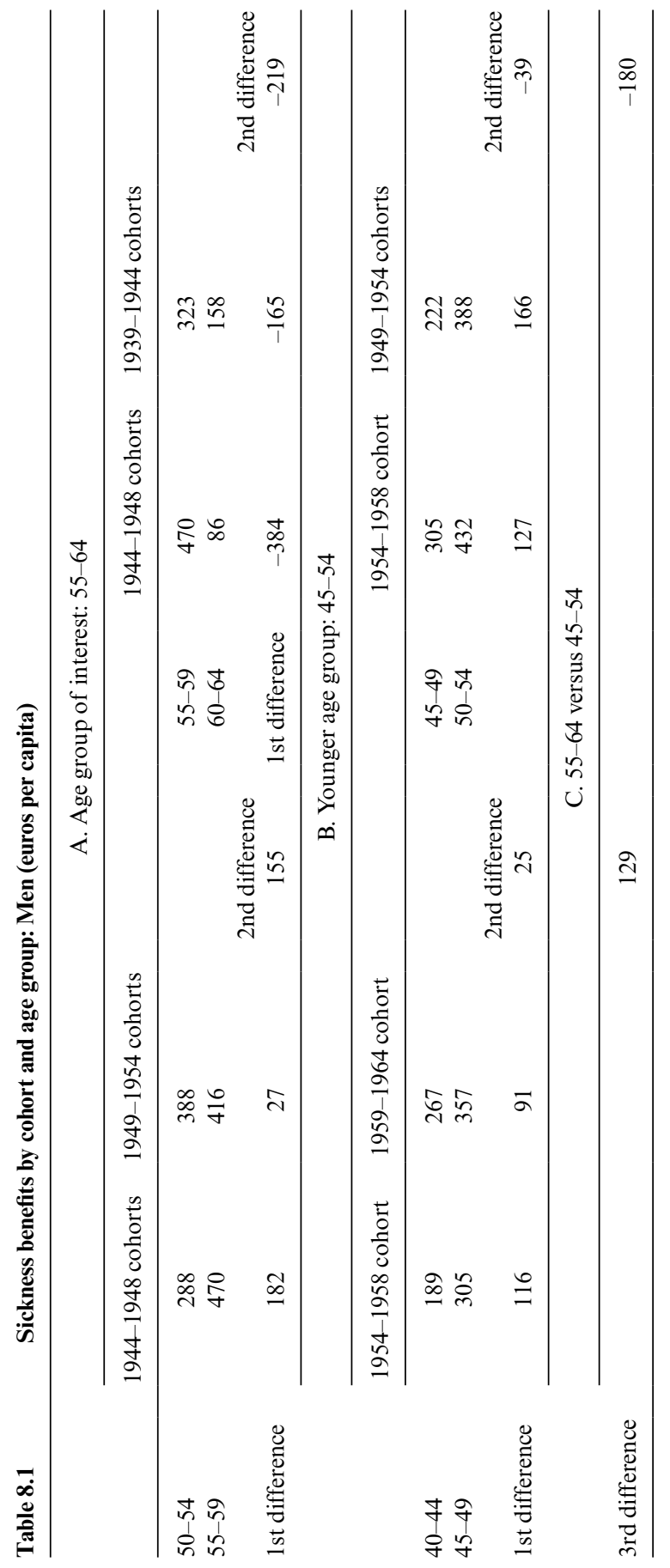


We control for this age effect using the 1949 to 1954 cohorts, observed in 2003 and 2008. At the age of fifty-five to fifty-nine, these cohorts witnessed tighter controls. Correspondingly, the increase of benefits is much lower; the difference in differences is 155 euros. In other words, the difference in differences shows that when workers are in their fifties, the reliance on sickness benefits increases much faster with age when controls are loose (for the 1944 to 1948 cohorts) than when they are getting tightened (for the 1949 to 1953 cohorts).

Consider now what happens between the fifty-five to fifty-nine and the sixty to sixty-four age ranges when controls get tighter. To do so, follow the 1944 to 1948 cohort again in 2003 and 2008 (a period of control tightening) and compare it to the 1939 to 1943 cohort in 1998 and 2003 (a period of loose controls). The results are given on the right part of table 8.1, panel A. For the 1944 to 1948 cohorts, benefits per capita strongly decreased between 2003 and 2008. Part of this is obviously due to an age effect: a large share of workers had retired by 2008 and was no longer eligible for sickness benefits. However, the comparison with individuals born between 1939 and 1943 shows that the drop is specifically large for the 1944 to 1948 cohorts: the difference in differences is -219 euros. $^{5}$

Overall, this shows that sickness benefits display a specific age pattern for the 1944 to 1948 cohorts that distinguishes them from the two adjacent cohorts: a very large increase between the ages of fifty to fifty-four and fifty-five to fifty-nine, followed by a dramatic fall when reaching the ages of sixty to sixty-four. As these cohorts reached the age of fifty-five to fiftynine just before a strong tightening of sickness benefit controls, a plausible explanation for this age pattern is the sensitivity of workers in the "crucial age" of fifty-five to fifty-nine to the rules governing the access to different pathways to retirement.

One may, of course, wonder whether similar patterns have occurred for younger cohorts on the same period. In panel B of table 8.1, we analyze the 1954 to 1958 cohorts using the two adjacent cohorts to control for age effects (in the same way as for panel A). We do find a rise in benefits between 1998 and 2003 (+25 euros, adjusting for age) and a fall between 2003 and 2008 ( -39 euros, net of age effects). However, the magnitude of these movements is much lower than for the 1944 to 1948 cohorts. This is confirmed by the third difference in panel $\mathrm{C}$.

Table 8.2 provides quite similar evidence for women, although the magnitude of the effects is somewhat lower. Overall, this analysis confirm that

5. Note that the 1939 to 1943 cohorts are better described as a "control" group than the 1949 to 1953 cohorts, as the former remained under a regime of loose controls, whereas the latter were impacted by the policy change: they reached the age of fifty-five to fifty-nine under a regime of tight controls. In that sense, the first difference-in-differences combines the effects of two opposite "treatments": increased access for the 1944 to 1948 cohorts (loose controls at age fifty-five to fifty-nine) contrasted to tightening of controls for the 1949 to 1953 cohorts. 


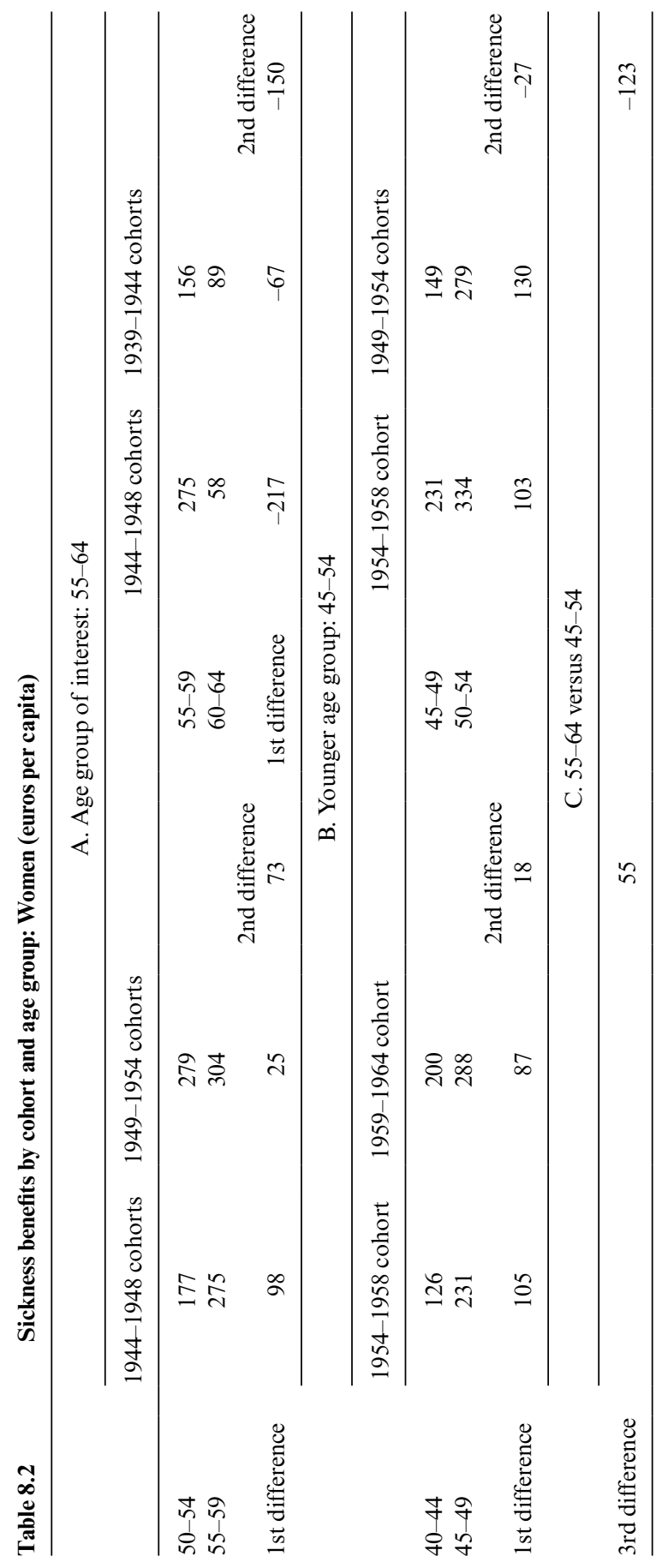


workers aged above fifty-five have "overreacted" to the rise and fall of sickness benefits over 2003. As this occurred in a context of restrictions of access to early retirement schemes, this evidence can be interpreted as a sign of the specific sensitivity of older workers to the rules of access to sickness benefits.

To conclude this section, we find robust evidence that sickness benefits and disability pensions can act as substitutes for other retirement routes, suggesting that older workers are quite sensitive to the financial incentives to use this route rather than other ones. Combined with the historical evidence on the important role played by disability routes before 1980, this suggests that today's low use of the disability route is mostly due to its relative unattractiveness.

\subsection{Increasing Health Inequalities among Seniors}

Previous sections have shown that disability can be used as a substitute for other retirement routes. This suggests that its apparent prevalence is not necessarily connected with changes in actual health status, and this also raises doubts about the role of adverse health conditions as a major explanation for the development of early retirement: the expansion of early retirement would have resulted from other factors, and the fact that it has sometimes taken the form of increased disability rates would only reflect country- or period-specific institutional arrangements.

But this may be only part of the story. A complete diagnosis of the link or the nonlink between early exits and health status requires a more direct examination. This last section will provide some elements on this issue both at the micro and the macro level, relying on various measures of health. Messages will require more or less qualification according to the perspective that is retained.

\subsubsection{Mortality Rates and Life Expectancy}

We first study the link between retirement and health trends proxying health by mortality. Mortality is an imperfect indicator of health or disability; however, it remains an important indicator of the change in health status of a population. Figures 8.9 and 8.10 provide mortality rates at different ages for men and women. The mortality rate at seventy has been divided by more than two between 1962 and 2000, but each age is concerned by the decrease. More than the mortality rate, the ages of equal mortality probability given in figure 8.11 provide an idea of the increase in the average length of life over the past decades. What is computed at each period is the age at which an individual reaches the same mortality rate as an individual aged, respectively, fifty-five, sixty, or sixty-five. On the average, for both men and women, these "equal mortality ages" have shifted by about ten years between 1960 and 2008. For instance, you need to be a little more than seventy today to face the instant mortality risk to which an individual aged sixty was exposed in 1960. 


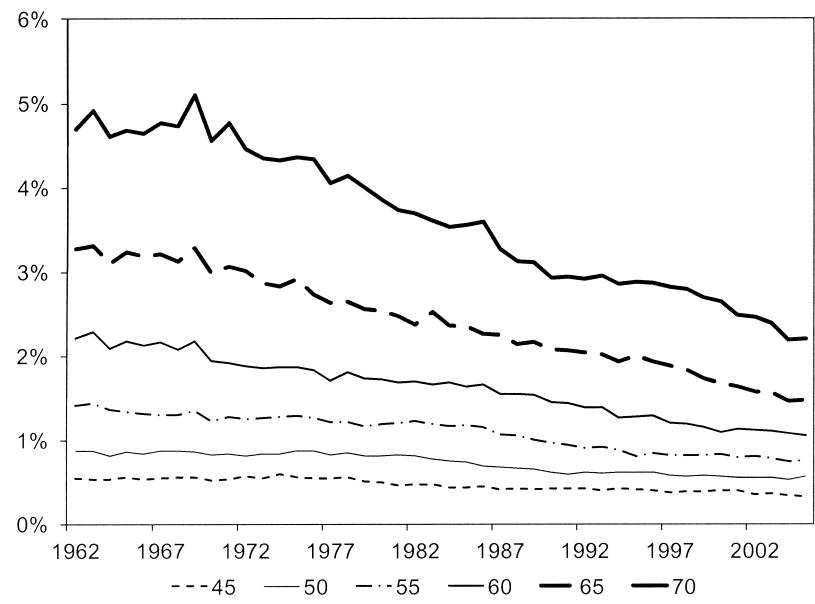

Fig. 8.9 Mortality rates at different ages, men

Source: INSEE.

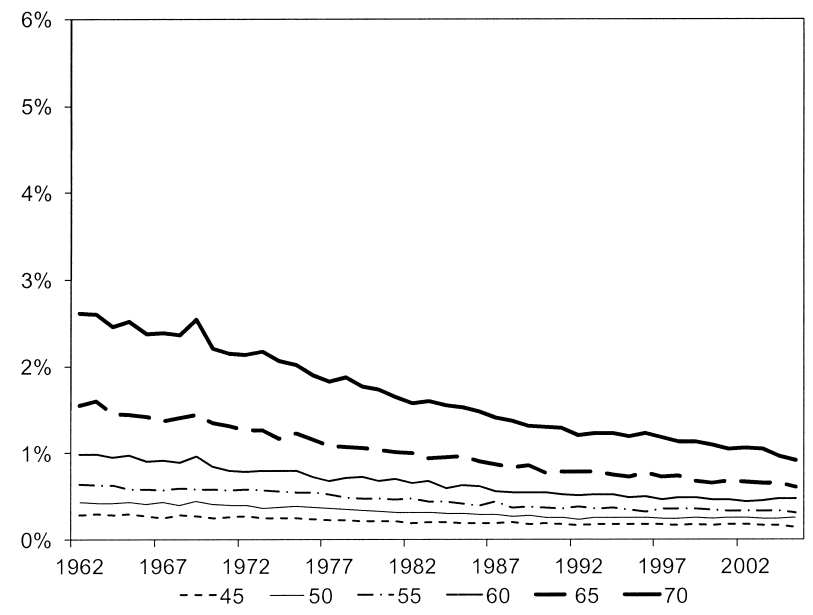

Fig. 8.10 Mortality rates at different ages, women

Source: INSEE.

This is more or less consistent with the global shift in life expectancy at birth that has gained 10.6 years for men and 10.7 years for women over the same period (respectively, from 67.0 to 77.6 years, and from 73.6 to 84.3 years).

Unsurprisingly, the comparison of labor force participation with such mortality data on figure 8.12 gives no indication of a link between health and labor force participation of older workers. If health is proxied by mortality, this approach sends a clear message of a full disconnection between health and retirement trends. 

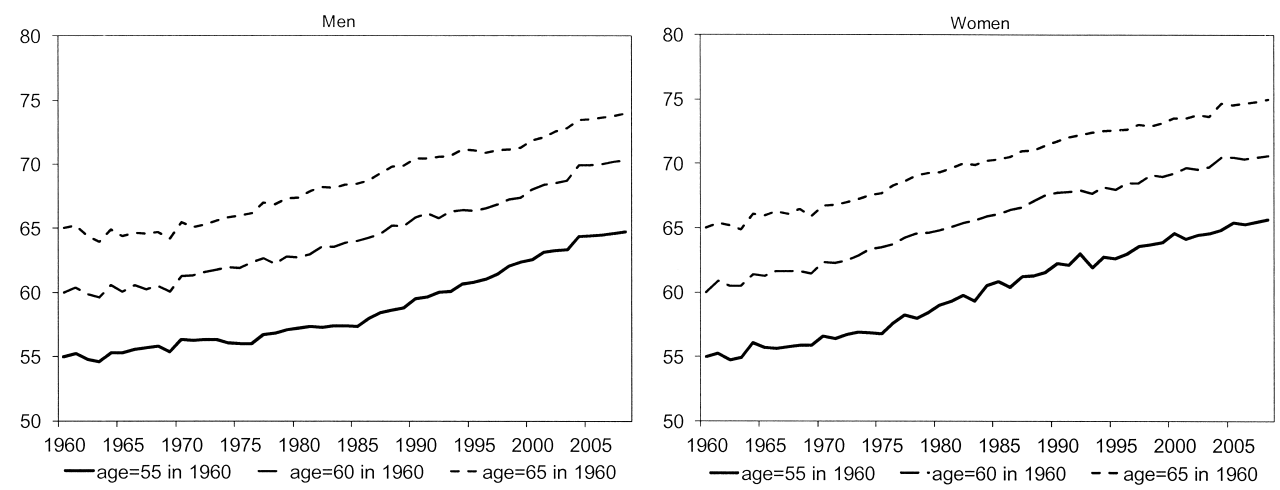

Fig. 8.11 Ages of equivalent mortality

Sources: INSEE and authors' computations.

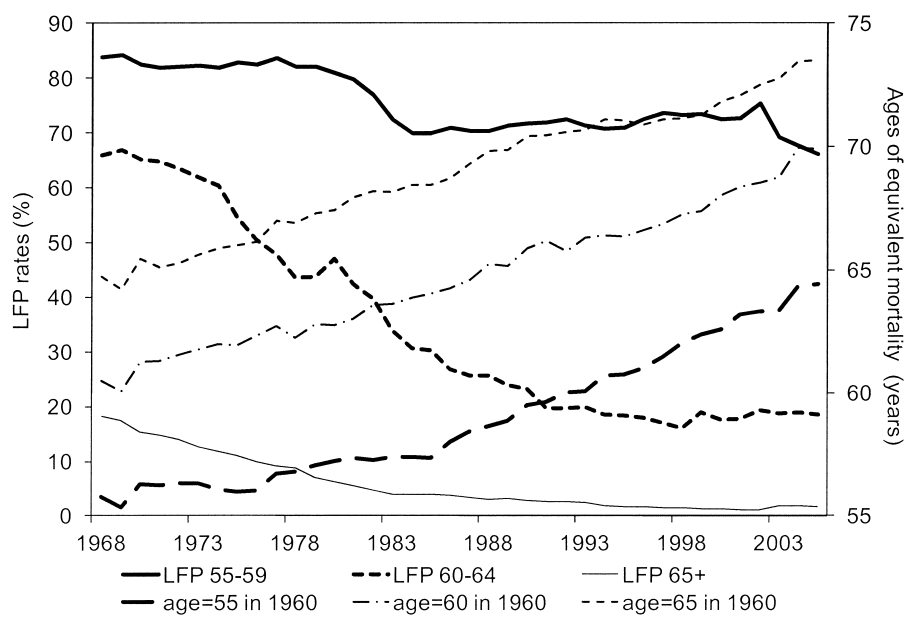

Fig. 8.12 Ages of equivalent mortality and labor force participation rates, men Sources: INSEE and authors' computations.

However, aggregate mortality rates suffer from limitations when assessing health trends. Although life expectancy in France is increasing, it is not clear whether these extra years are spent in good health. For Jagger et al. (2008), at fifty years of age, life expectancy in France is 29.6 years for a man and 35.4 years for a woman, whereas healthy life expectancy is 18.0 years for a man and 19.7 years for a woman. ${ }^{6}$ Moreover, the aggregate trend may hide changes in the dispersion of health.

6. These authors calculate the differences between life expectancy and healthy life years in all the countries using mortality data in the form of life tables and age specific prevalence of activity limitation. The results showed that in twenty-five countries, a fifty-year-old man can expect, on average, to live until 67.3 years old without activity limitation and a woman until 68.1 years old, whereas a man's life expectancy is 78.9 years and a woman's is 83.5 years. The 
Several alternative health indicators can be used to study these changes in health status both at the macro and micro levels over the last decades. We shall concentrate here on two of them: self-reported health and the body mass index (BMI), both available since 1992 from the Enquête Santé et Protection Sociale (ESPS), which is a biennal survey on a panel of beneficiaries from health insurance, performed by IRDES (Institut de Recherches et de Documentation en Economie de la Santé).

\subsubsection{Self-Reported Health Status}

Figures 8.13 and 8.14 show the average self-reported health level on a scale of 10, for various age groups, for men and women. They do not show any clear trend over the last twenty-years but point at a slight deterioration over recent years (2002 to 2008). At the micro level, it can also be checked that subjective health indicators are clearly lower for disabled. Looking by employment status shows also an increasing gap between unemployed and employed older workers. For men, we note a monotonic decline in subjective health status of unemployed over the period, health status of other categories being almost constant. Results are less clear for women even if there is a decrease at the end of the period for the unemployed ones.

Globally, messages delivered by these subjective health indicators do not run completely opposite to those obtained with mortality data. We do not find a massive global deterioration of health status that could account for observed declines in employment rates. Global trends rather suggest that health factors have been globally neutral over the period. But micro data suggest that that health factors may have eventually fed pressure for maintaining early retirement over the very recent years. Even if there is no strong correlation between health status and retirement along the time dimension, this correlation does exist at the micro level. Bad health is correlated to nonemployment and is, therefore, a reasonable candidate for explaining part of early exits.

This micro link can come under various forms. It is straightforward when exit takes place through the disability route. It will be more indirect but still easy to figure out when exit takes place through unemployment. On the demand side, workers in bad health are more likely to suffer from belowaverage productivity and are more likely to be laid off by firms confronted to excess capacity or in search of productivity gains. The probability of being hired, already low for all senior job seekers, will also be still lower for those in bad health. On the supply side, these workers in bad health are more likely to find attractive and accept financial conditions offered in case of individual

differences or inequalities between countries are considerable both in terms of life expectancy (9.1 years for men and 6.1 years for women) and healthy life expectancy (14.5 years for men and 13.7 years for women). On the basis of a cross-country econometric analysis, the authors demonstrate that disability-free life expectancy is related to a country's gross domestic product (GDP) and health expenditures in the care for the elderly of both sexes. For men, it is positively correlated to the long-term unemployment rate and negatively correlated to lifelong learning. 

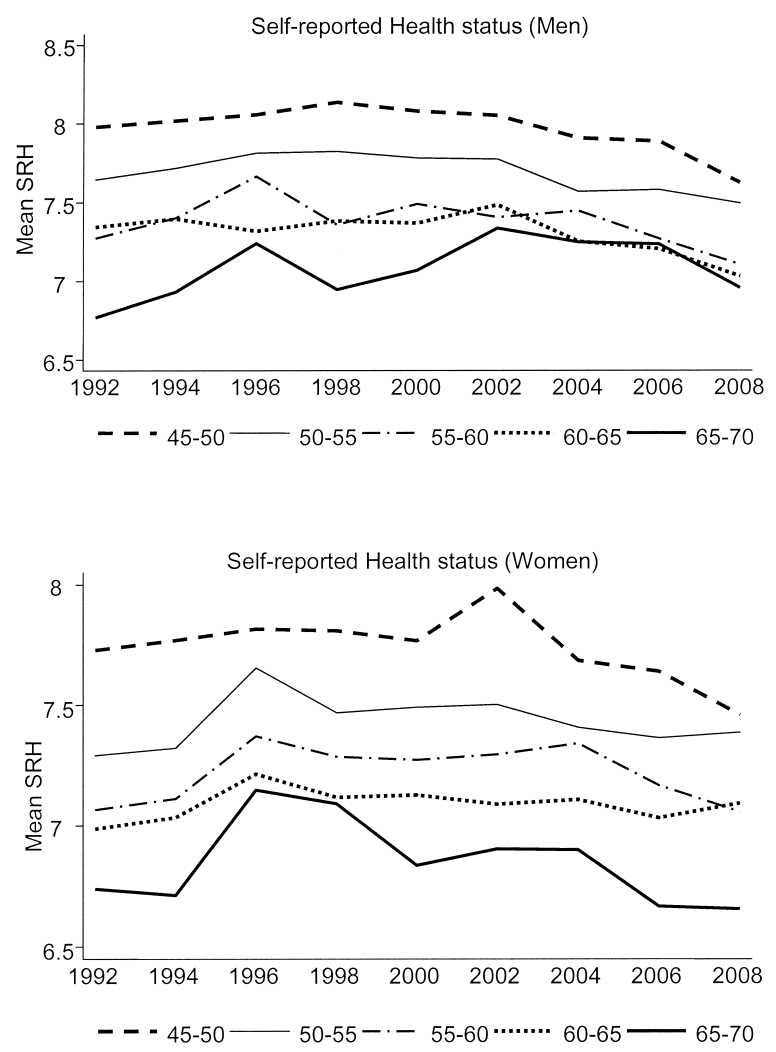

Fig. 8.13 Self-reported health status

or collective layoffs and, when out of the labor force, will be less motivated for trying to return to employment.

We must recall, however, that quantification of these links may be affected by various biases or measurement errors. For instance, the causal impact of health on employment can be either moderated or amplified by symmetrical effects of labour force status on health: being in employment can be the cause or an aggravating factor of some health problems (Strauss and Thomas 1998), especially for people working under conditions of physical or psychological pressure, but unemployment can also be a negative factor for health. Depending upon which effect dominates, the observed relationship between health and employment will underestimate or overestimate the true causal impact of health.

Biases can also come from declarative behaviour. An increasing sensitivity to a health problem can lead to a stationary or deteriorating index of self-reported health, even when objective health improves. The correlation observed at the micro level between nonemployment and bad health can also result from self-justification bias, that is, people preferring to attribute 
Men (aged 50-65)

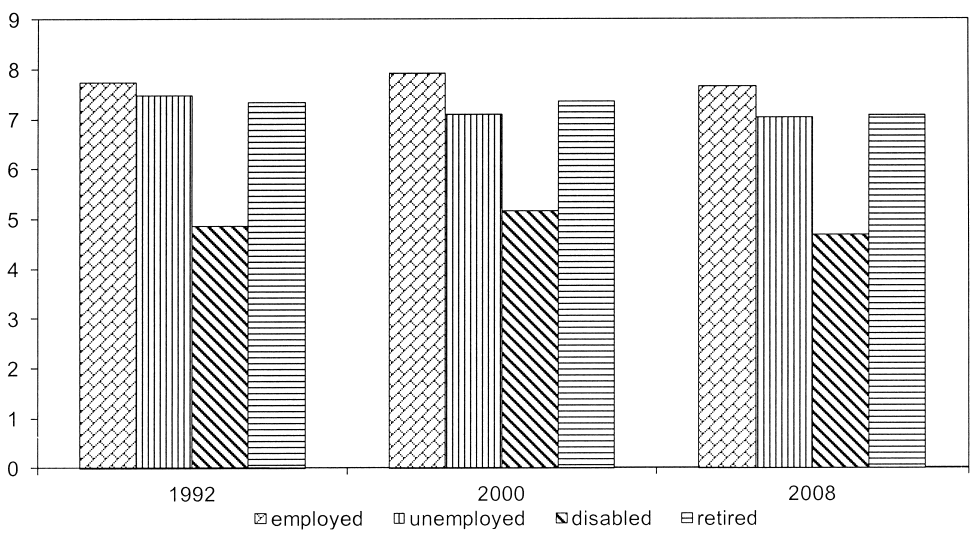

Women (aged 50-65)

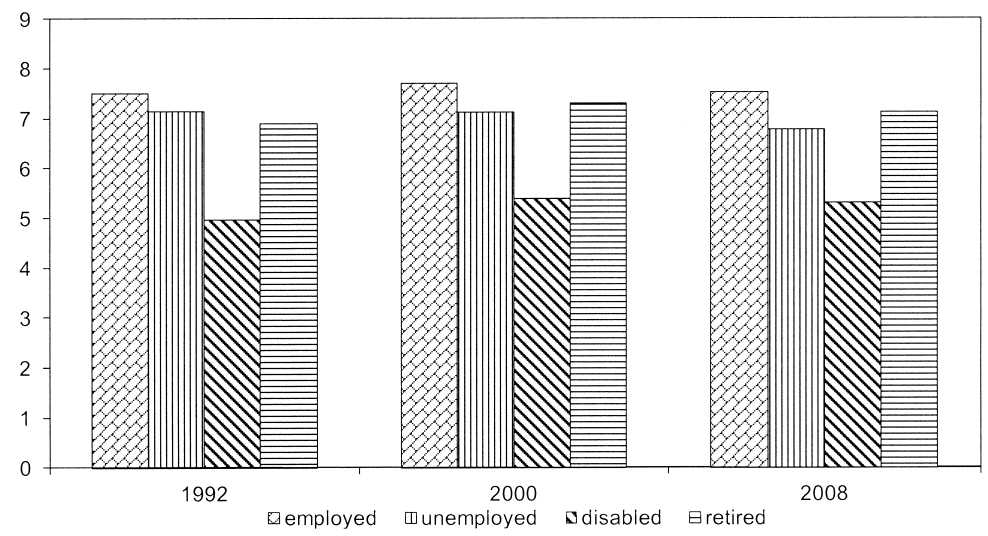

Fig. 8.14 Self-reported health status by labor market status

their early exit from the labor force to health problems rather than to any other possible cause.

\subsubsection{The Body Mass Index}

This latter category of biases due to self-declaration can be avoided by relying on more objective measures. The one we favor here is the body mass index, widely accepted in the medical and public health literature as an index of bad health because it represents a risk factor of health disorders and premature mortality. Body mass indexes by age and gender are given on table 8.3. On average, the BMI increases consistently during the period 1992 to 2008. For men aged between fifty and sixty-five years old, it increases from 25.9 in 1992, to 26.3 in 2000 and to 26.4 in 2008 . For women aged between fifty and sixty-five years old, it was lower at the beginning of the period (24.7 
Table 8.3

Body mass index (BMI) by period, gender, and age group

\begin{tabular}{|c|c|c|c|c|}
\hline & Mean & $\begin{array}{l}\text { Standard } \\
\text { deviation }\end{array}$ & $\%$ with $\mathrm{BMI}>25$ & $\%$ with $\mathrm{BMI}>30$ \\
\hline \multicolumn{5}{|c|}{ 50-65 age group } \\
\hline \multicolumn{5}{|l|}{ Men } \\
\hline 1992 & 26.0 & 3.5 & 57.0 & 11.8 \\
\hline 2000 & 26.2 & 3.5 & 56.3 & 12.3 \\
\hline 2008 & 26.4 & 3.9 & 61.5 & 16.1 \\
\hline \multicolumn{5}{|l|}{ Women } \\
\hline 1992 & 24.7 & 4.1 & 40.1 & 10.8 \\
\hline 2000 & 25.0 & 4.4 & 42.7 & 13.7 \\
\hline 2008 & 25.2 & 4.7 & 43.3 & 15.4 \\
\hline \multicolumn{5}{|c|}{ All ages } \\
\hline \multicolumn{5}{|l|}{ Men } \\
\hline 1992 & 22.7 & 4.5 & 29.4 & 5.0 \\
\hline 2000 & 23.0 & 4.8 & 32.9 & 6.5 \\
\hline 2008 & 23.5 & 5.0 & 37.1 & 9.1 \\
\hline \multicolumn{5}{|l|}{ Women } \\
\hline 1992 & 21.9 & 4.5 & 20.8 & 5.3 \\
\hline 2000 & 22.2 & 4.8 & 23.4 & 6.9 \\
\hline 2008 & 22.9 & 5.3 & 29.3 & 9.9 \\
\hline
\end{tabular}

Sources: ESPS surveys and authors' calculations.

against 25.9 for the men), but it increases also from 24.7 in 1992, to 25.0 in 2000 , and to 25.2 in 2008. This increase does not seem to be that large: averages still do not contradict the view that health factors have been relatively neutral over the period. But other distributional characteristics deliver a less favorable message, especially at the top of the distribution. If we define a BMI $>30$ as obesity, its prevalence between 50 and 65 has increased by about 30 to 40 percent between 1992 and 2008, from 11.8 to 16.1 for men and from 10.8 to 15.4 for women. The phenomenon is still more striking for younger ages, with a prevalence that has been almost multiplied by two for the entire population. This suggests a generation effect that may accelerate health deterioration in the fifty to sixty-five group over the decades to come. This provides one good reason to believe that some pressure will persist or even increase in favor of specific measures in favor of people reaching retirement ages under adverse health conditions, and it points to the necessity of looking simultaneously at means and at dispersions if we want to measure properly the magnitude of this problem.

Finally, correlations between BMI levels and employment status exhibit a less clear pattern than for subjective health. However, it shows that the BMI, for both men and women, is almost always higher for disabled individuals and lower for individuals in employment. Except for men at the end of the period, the BMI indicator is higher for unemployed than for employed older workers. This confirms the results we had with the subjective health 

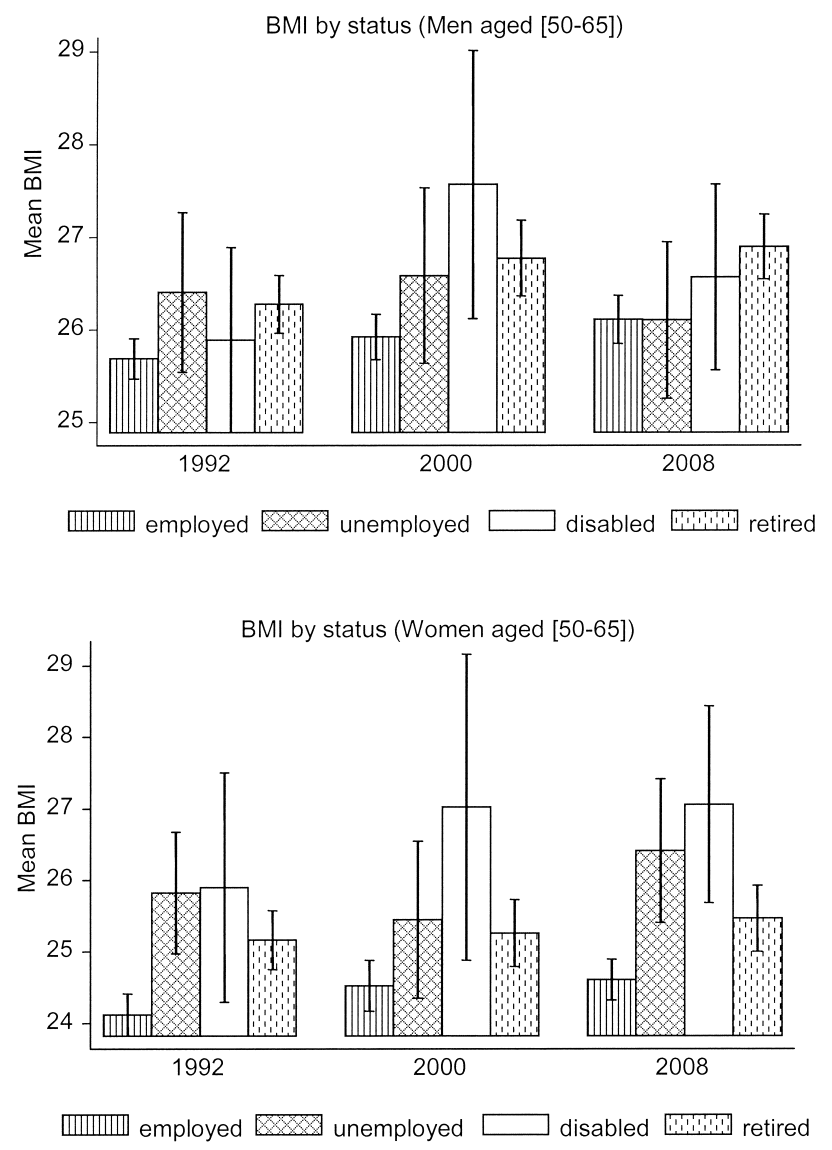

Fig. 8.15 Body mass index indicator by labor market status

indicator. Unemployed people seem to be in a worth health than employed people. As previously, unemployment may act as a substitution to disability routes but acting on people with health difficulties, and the question is to know how pension policy must address the case of these people. Again, the question is all the more important that BMI trends among younger cohorts suggest that the problem may gain further importance over the decades to come. (See figure 8.15.)

\subsection{Conclusion}

Even if disability doesn't seem to be a key component in the retirement history of old workers in France, discussions on disability as a retirement route remain essential in a context of a general decrease in the generosity of the pension scheme. 
The study of the past reforms of the pension system underlines that disability routes have often acted as a substitute to other retirement routes. Changes in the claiming of disability benefits seem to match changes in pension schemes or controls more than changes in such health indicators as the mortality rates. However, the last section suggests increases in average health levels over the past two decades have come along with increased disparities. In that context, less generous pensions may induce an increase in the claiming of disability benefits partly because of substitution effects but also because the share of people with poor health increases.

\section{References}

Barnay, T., and F. Jeger. 2006. "Quels dispositifs de cessation d'activité pour les personnes en mauvaise santé?" ("Which Exit Routes for People in Bad Health?") Drees-Etudes et Résultats 492.

Ben Salem, M., D. Blanchet, A. Bozio, and M. Roger. 2010. "Labor Force Participation by the Elderly and Employment of the Young: The Case of France." In Social Security Programs and Retirement around the World: The Relationship to Youth Employment, edited by J. Gruber and D. Wise, 119-46. Chicago: University of Chicago Press.

Blanchet, D., and T. Debrand. 2008. "The Sooner, the Better? Analyzing Preferences for Early Retirement in European Countries." IRDES Working Paper no. 13.

Bozio, A. 2006. Réforme des retraites: Estimation sur données françaises." "Social Security Reforms: Estimation on French Data.") PhD diss., EHESS, Paris.

Jagger, C., C. Gillies, F. Moscone, E. Cambois, H. van Oyen, W. Nusselder, and J. M. Robine. 2008. "Inequalities in Healthy Life Expectancies in EU25." Lancet $14: 1-8$.

Kusnik-Joinville, O., C. Lamy, Y. Merlière, and D. Polton. 2006. "Déterminants de l'évolution des indemnités journalières maladie." ("Determinants of Changes in Sickness Benefits.") CNAMTS Points de Repère 5.

Lê, F., and D. Reynaud. 2007. "Les indemnités journalières." ("Sickness Benefits.") Drees-Etudes et résultats 592.

Molinié, A.-F. 2006. "La santé au travail des salariés de plus de 50 ans." Données Sociales, INSEE.

Omnès, C. 2006. "Hommes et femmes face à la retraite pour inaptitude de 1945 à aujourd'hui." ("Disability Pensions for Men and Women since 1945.") Retraite et Société 49:77-97.

Strauss, J., and D. Thomas. 1998. "Health, Nutrition, and Economic Development." Journal of Economic Literature 36 (2): 766-817.

Struillou, Y. 2003. Pénibilité et retraites. (Hard Working Conditions and Retirement.) Rapport remis au Conseil d'Orientation des Retraites.

Volkoff, S., and F. Bardot. 2004. "Départs en retraite, précoces ou tardifs: À quoi tiennent les projets des salariés quinquagénaires?" "Early or Late Retirement Ages: What Determines the Plans of Workers above Fifty?") Gérontologie et Société 111:71-94. 